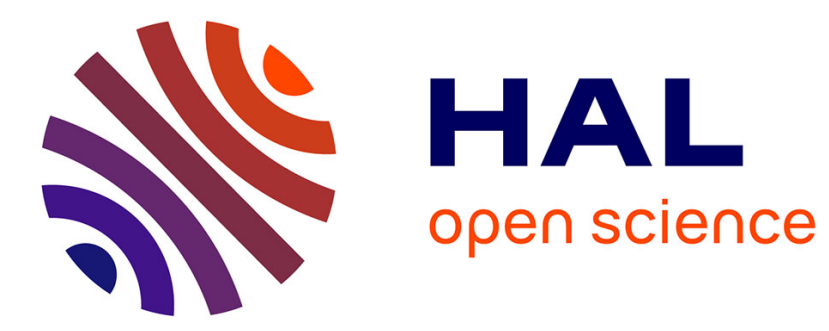

\title{
Methodology of seasonal morphological modelisation for nourishment strategies on a Mediterranean beach
} Philippe Larroudé

\section{To cite this version:}

Philippe Larroudé. Methodology of seasonal morphological modelisation for nourishment strategies on a Mediterranean beach. Marine Pollution Bulletin, 2008, 57 (1-5), pp.47-52. 10.1016/j.marpolbul.2008.04.039 . hal-00357635

\section{HAL Id: hal-00357635 \\ https://hal.science/hal-00357635}

Submitted on 3 Apr 2020

HAL is a multi-disciplinary open access archive for the deposit and dissemination of scientific research documents, whether they are published or not. The documents may come from teaching and research institutions in France or abroad, or from public or private research centers.
L'archive ouverte pluridisciplinaire HAL, est destinée au dépôt et à la diffusion de documents scientifiques de niveau recherche, publiés ou non, émanant des établissements d'enseignement et de recherche français ou étrangers, des laboratoires publics ou privés. 


\title{
Methodology of seasonal morphological modelisation for nourishment strategies on a Mediterranean beach
}

\author{
Philippe Larroudé \\ Laboratoire des Ecoulements Géophysiques et Industriels, LEGI, BP 53, Grenoble, France
}

A modified 2DH morphodynamical model was employed to simulate the evolution of large-scale features with major implications for beach nourishment. The study was focused on modelling the evolution of material artificially placed in different parts of the profile, extracting or adding material to the natural bars, and quantifying how the profile responds to different wave climates and nourishment placements. The simulated results were compared with field data from a Mediterranean beach.

\section{Introduction}

Examples of nourishment tests carried out on the near shore zone are few and far between in relevant literature, compared to the number undertaken directly on the beach. SAFE, the latest European project within the MAST program, acknowledges the absence of reference documents on this question, although such a technique could presumably constitute a less costly alternative (Hamm et al., 2002).

The use of offshore bars to fight beach erosion, dating back to the $90 \mathrm{~s}$, was based on the fact that they represented a substantial reservoir of sediments. That theory turned out to be irrelevant, as beach nourishment requires coarser grain sizes. However, the essential role these bars can play in wave mitigation was shown by recent studies. Hence, working on reinforcing existing bars or even adding extra bars is a convincing approach, for they constitute a line of defence with no visual impact and are therefore environment-friendly. The method offers the added benefit of tapping abundant fine sands which are easily available offshore, to build up the bars.

In addition, adequate depths in the inner shelf area would facilitate dredging and discharge operations and as the material reclaimed is usually clean, it can therefore be used directly without any processing. The core of the additional bar could also be made from marine muds, which are equally easily available. All these assumptions should, of course, be systematically checked, the purpose of the exercise being to assess, through mid-term bathymetric evolution simulation, the consequences of the implementation of offshore bar nourishment and define the best location.

E-mail address: larroude@hmg.inpg.fr
The understanding of these processes needs, at this time, in situ data but also the development of mathematical models and numerical codes. Hence, following the work of De Vriend (1987) and De Vriend and Stive (1987), we tried to improve the classic quasi-steady procedure. The objectives of this work will be therefore to mode and to simulate processes of sedimentary transport on sandy beaches with varied weather conditions in the medium term time scale (from a few days to a few months).

\section{Procedure and description of the beach}

Certain and Barusseau (2006) showed that the morphodynamic evolution of offshore bars in a microtidal environment and bimodal moderate wave regime follows two different conceptual models, the main one being a seasonal pattern in line with the observed cycle of hydrodynamic conditions.

The morphological evolution in the near shore region, including its large-scale features, was first investigated using a combination of a commercial 2DH model and a Multi1DH model (Camenen and Larroudé, 2003a,b). Simulation of the wave-driven currents was carried out with Telemac, a finite-volume elements model, and the Sisyphe sand transport module served to compute sediment transport rates and bed evolution. Since the sediment transport in the surf zone is mainly controlled by undertow, an undertow model (based on Svendsen, 1984) was added to account for that process.

These models were used in the framework of a simulated meteorological cycle describing the seasonal evolution of hydrodynamic factors. Results from monthly 2DH evolution simulations showed a perfect fit with field data obtained on the "plage de la Corniche" in Sète (Southern France) (the site is presented in Certain, 2002). 

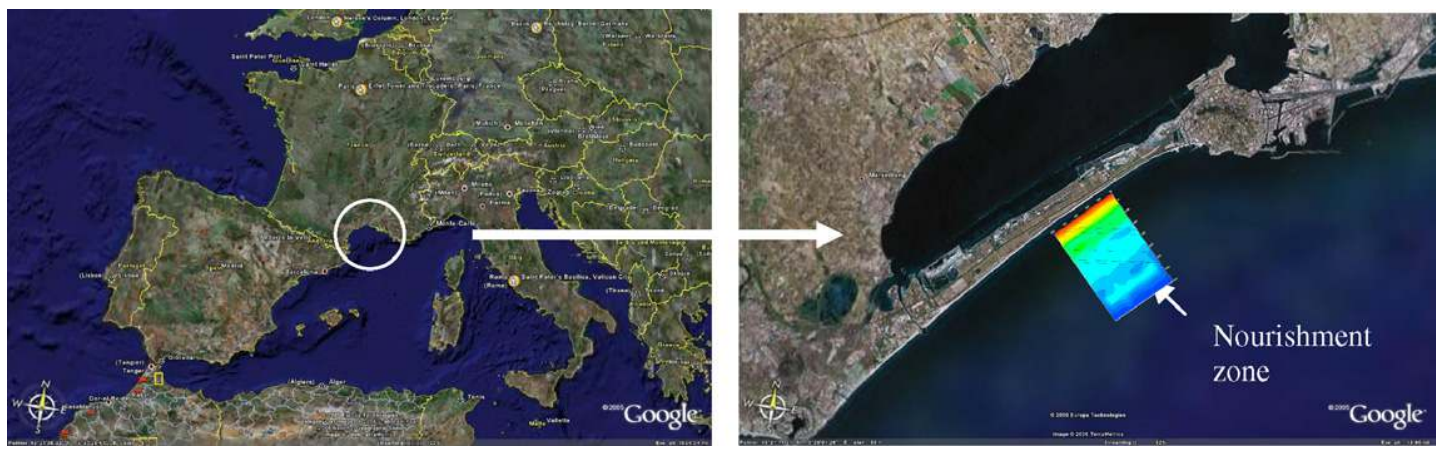

Fig. 1. Localisation of the "plage de la Corniche", France, Mediterranean sea coast, and zoom on the study area with the creation of an artificial offshore bar.

Morpho-hydrodynamic feedback of a bar having undergone reinforcement is also examined (see Fig. 1).

\section{The codes}

The sedimentary evolution was modelled under the action of the oblique incident waves and was coupled with different numerical tools dedicated to the other process involved in the near shore zone. We can mention the following modules:

- a wave module takes into account the surge energy dissipation (hyperbolic equation of extended Berkhoff), (LNHE, Artemis, 2002). The Artemis code (Agitation and Refraction with Telemac2d on a MIld Slope) solves Berkhoff equation taken from Navier-Stokes equations with some other hypothesis (little camber of the surface wave, little slope...). The main results are, for every node of the mesh, the height, the phase and the incidence of the waves. Artemis can take into account the reflection and the refraction of waves on an obstacle, the bottom friction and the breakers. One of the difficulties with Artemis is that a fine mesh must be used to have good results whereas Telemac2d do not need such a fine mesh;

- a module that calculates currents induced means by the surge of the waves, from the concept of radiation constraints obtained according to the module of waves, (LNHE, Telemac2d, 2002). Telemac2d is designed to simulate the free surface flow of water in coastal areas or in rivers. This code solves Barré Saint-Venant equations taken from Navier-Stokes equations vertically averaged. Then, main results are, for every node of the mesh, the water depth and the velocity averaged over the depth. Telemac $2 \mathrm{~d}$ is able to represent the following physical phenomena: propagation of long periodic waves, including non-linear effects, wetting and drying of intertidal zone, bed friction, turbulence;

- a sedimentary module integrating the combined actions of the waves and the wave currents (2D or 3D) on the transport of sediment, (LNHE, Sisyphe, 2002). The Sisyphe code solves the bottom evolution equation which expresses the conservation of matter using directly a current field result file given by Telemac2d. Four of the most currently empirical or semi-empirical formulas are already integrated in Sisyphe (Peter-Meyer, Einstein-Brown, Engelund-Hansen and Bijker formulas). We integrated two others which seem more appropriate to coastal sediment transport (Bailard, 1981; Dibajnia and Watanabe, 1992). The main results are, for every node of the mesh, the bottom evolution and the solid transport. The equations of the three modules are detailed in Hervouet (2007). This methodology was tested and explained for morphodynamic simulations in Falqués et al. (2008);

- a hydrodynamic simplified model (called Multi1DH) used the following assumptions: a random wave approach, in a $1 \mathrm{DH}$ (cross-shore) direction. An offshore wave model (shoaling + bottom friction + wave asymmetry) was used with the break point estimation. The waves in the surf zone were modelled with the classic model of Svendsen (1984) with an undertow model (roller effect, Svendsen, 1984; Dally et al., 1984). As a long shore current model, we used the Longuet Higgins's model (1970). This model was already used and tested in Camenen and Larroudé (2003b).

\section{Results}

\subsection{Comparison for validation}

Firstly we set up a procedure to use the coupled codes ArtemisTelemac2d-Sisyphe and more particularly we improved the treatment of the boundary conditions in order to be able to work on fields of calculations close to the coastal zone and equivalents in dimension for the three codes. We also used the Multi1DH code for the medium term simulations. Both these models take into account the breaker zone of waves as presented in paragraph 3. On the other hand only the parametric model can represent the set up. This methodology of morphodynamic modelling for sandy beaches was already improved in terms of mesh, time step and convergence in Camenen (2002), Larroudé and Camenen (2004) and Falquès et al. (2008). These models were used for monthly simulations taking account the weather conditions. These weather conditions were drawn from the ground data for the period of November 2000 and were simplified in terms of height of swell, period of swell and direction by dividing the month into 9 significant periods (see Table 1). One can notice that using the average height of the swells during each simulation period attenuated the weather events this November.

We obtain a good adequacy between numerical bathymetries after one month and those raised on the ground (see Fig. 2).

We began simulations with a nourishing of the study zone at the beginning of November 2000 and we could compare the results

Table 1

Simplified weather data: November 2000 ( $\theta$ angle in degree in the trigonometrically direction reverses compared to the normal with the beach)

\begin{tabular}{llll}
\hline Time & Hs $(\mathrm{m})$ & Tp $(\mathrm{s})$ & $\theta$ \\
\hline 0j à 1j 21 h & 0.244 & 7.45 & 25.475 \\
1j 21 h à 3j 12 h & 1.703 & 7.92 & 27.861 \\
3j 12 h à 7j 21 h & 0.351 & 7.13 & 28.094 \\
$7 \mathrm{j} 21$ h à 10j 9 h & 1.787 & 6.76 & 6.065 \\
10j 9 h à 18j 12 h & 0.222 & 6.2 & 3.97 \\
18j 12 h à 20j 3 h & 1.358 & 6.78 & 14.9 \\
20j 3 h à 24j 15 h & 0.251 & 7.03 & 14.33 \\
24j 15 h à 30j & 1.259 & 6.27 & -5 \\
\hline
\end{tabular}



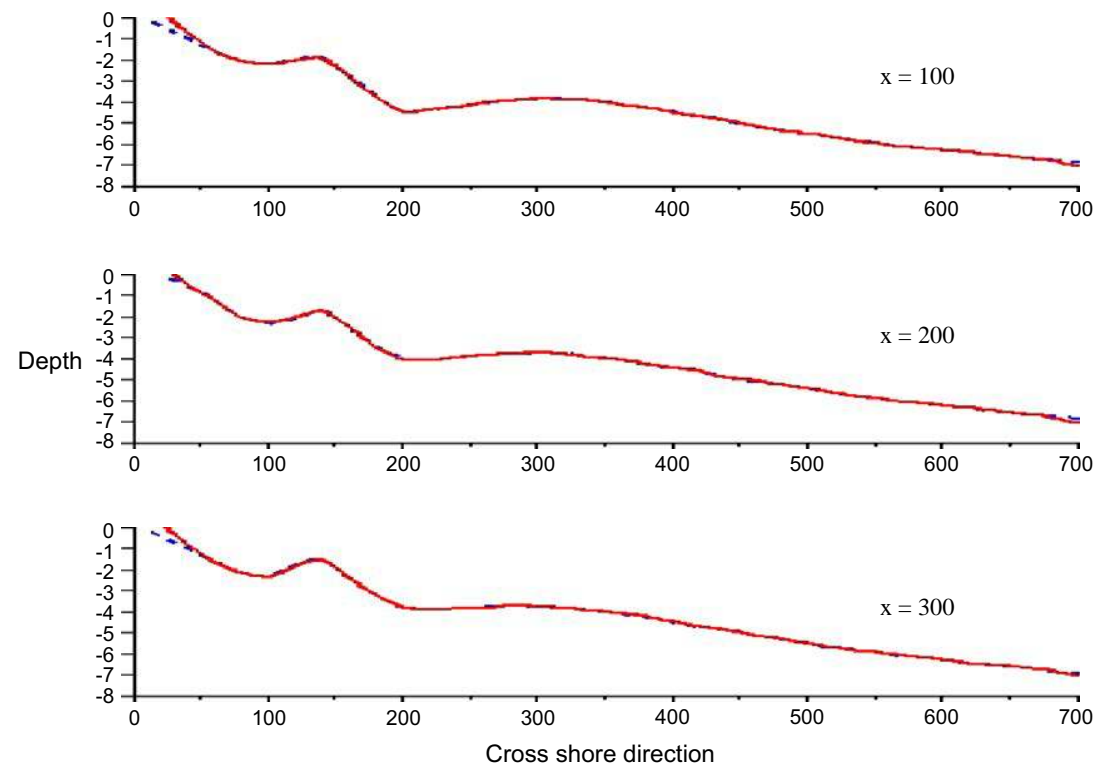

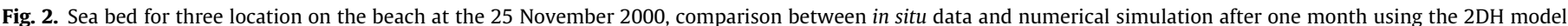
with the meteorological model.

obtained with model 2DH (waves, hydrodynamics and transport) and the simplified model Multi1DH.

Secondly, we regarded as basic state a profile of the bathymetry of November 16, 2000, the P5 profile with $X=200 \mathrm{~m}$ (longshore distance compared to the beginning of the study zone). This approach enabled us to more easily compare the models of calcula-

Table 2

Weather data simplified for the three cases of storm ( $\theta$ angle in degree in the trigonometrically direction reverses compared to the normal with the beach)

\begin{tabular}{lllll}
\hline & Time $(\mathrm{h})$ & Hs $(\mathrm{m})$ & $\mathrm{Tp}(\mathrm{s})$ & $\theta$ \\
\hline TS & 24 & 1 & 6.5 & $0^{\circ}$ and $20^{\circ}$ \\
FS & 24 & 2.5 & 7 & $0^{\circ}$ and $20^{\circ}$ \\
ES & 24 & 4 & 10 & $0^{\circ}$ and $20^{\circ}$ \\
\hline
\end{tabular}

tion used by the various partners of the program. For these simulations we agreed to consider three cases of climatic conditions (see Table 2): Traditional Storm (TS), falling from Storm (FS) and Exceptional Storm (ES). All the simulations were carried out with the model Multi1DH and the results will be presented later. We also made some calculations with the chain of ArtemisTelemac2d-Sisyphis code.

In the case of FS, the swells do not have any effects on the internal and external bars. For TS simulations the swells erode the internal bar but do not seem to attack to a significant degree, the beach and the external bar. Only one longer-term erosion of the internal bar can be prejudicial for the protection of beach.

The case of the exceptional storms was used as a basis to present the differences obtained with the model Multi1DH between the different recharging option. The case, on the basic profile of
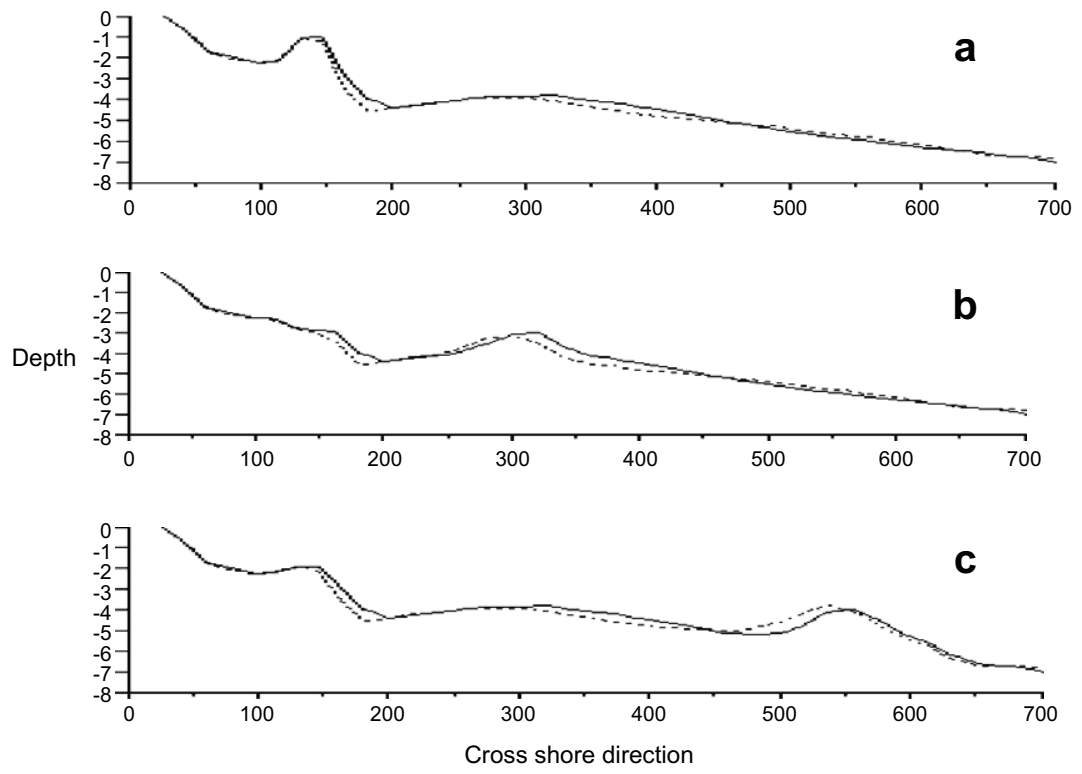

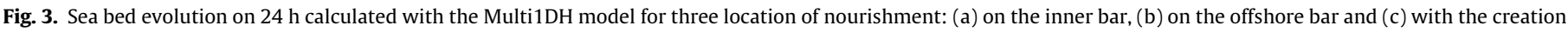
of new bar offshore. 

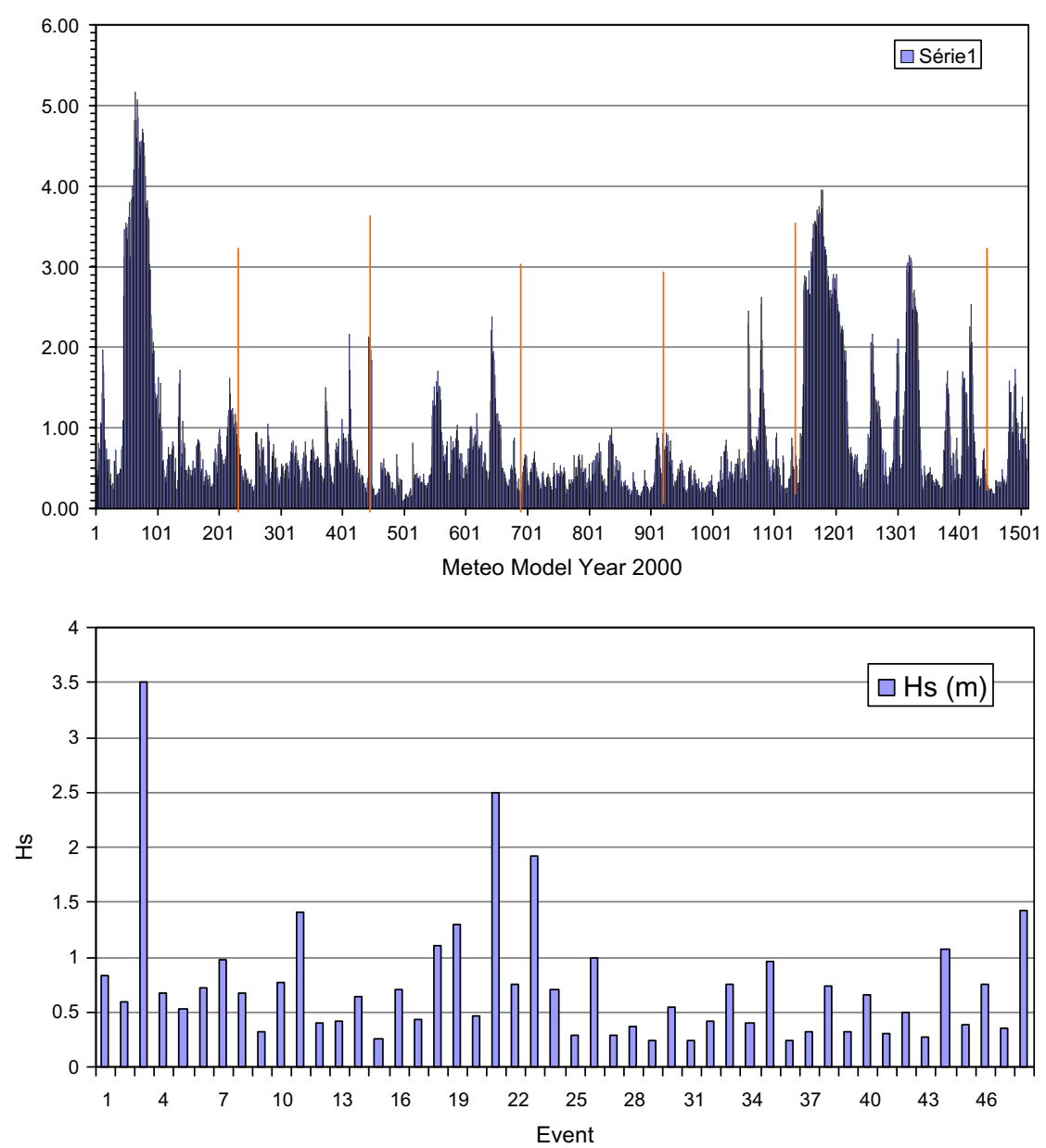

Fig. 4. The meteorological model is based on the data (Certain, 2002) collected on the "plage de la Corniche" in Sète during the year 2000.

November 16, 2000, shows us an erosion of the internal and external bars with a transport of these bars further offshore and thus one can consider a weakening of the protection of the beach (see
Fig. 3). The internal bar was eroded of approximately $10 \mathrm{~m}$ and the external bar of $40 \mathrm{~m}$, the deposit offshore with a maximum of $25 \mathrm{~m}$ is very spread out. (a) November 2000

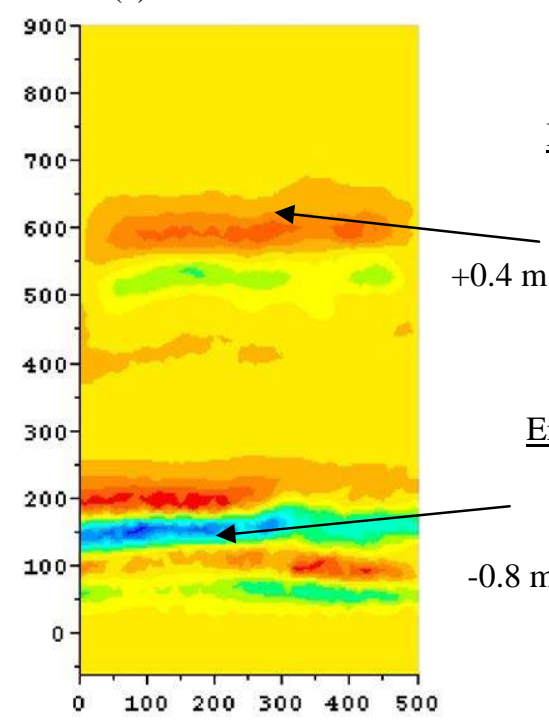

(b) November $2000+\mathrm{T} 2$

Offshore

$\mathrm{T} 2: \mathrm{Hs}=4 \mathrm{~m}, \mathrm{Tp}=10 \mathrm{~s}$ for a period of $39 \mathrm{~h}$

Fig. 5. (a) Sea bed evolution for a monthly simulation from the 4 November to the 25 November 2000 with nourishment and (b) the same with a storm of 39 h. 
These values are indicative of a possible comparison with other simulations but cannot be used as quantitative values for real estimates of the quantities of sands put into motion. We will further see that these values are still strongly dependent on the models and in particular on the formulas of sedimentary transport.

\subsection{Long term simulation}

The accuracy of this first result allowed us to create a methodology of simulation for a longer time scale. We are now looking with the coupled codes Artemis-Telemac2d-Sisyphe, the morpho-evolution of the beach with and without nourishment. The aim was to find the best way to create the simplified meteorological model from the in situ data. In the study presented in the paper, we show the first step of this methodology which is to compare seasonal simulation with different script of meteorolog- ical events during each season. The principal question is do we have to cut out each hour, day? Each meteorological event has time duration issued from the data (see graphics on Fig. 4). Figs. 5 and 6 show the importance of the storm in the destruction of the offshore nourishment bar. The major modification of the sea bed was numerically obtained because the time loop of the coupled codes Artemis-Telemac2d-Sisyphe was shorter than the time duration of the storm. The principal criteria to cut out could be the current velocity due to the waves. Indeed, when we have calm weather condition (e.g. small waves height) the feedback between the hydrodynamics and the sea bed evolution could be longer. Figs. 7 and 8 show the numerical difference due to number of hydro-sedimentary loop we simulated for the same monthly or seasonal modelling. The differences are very important in the very near shore region and close the beach. Fig. 8 shows a complete year of simulation (the 4 seasons) with

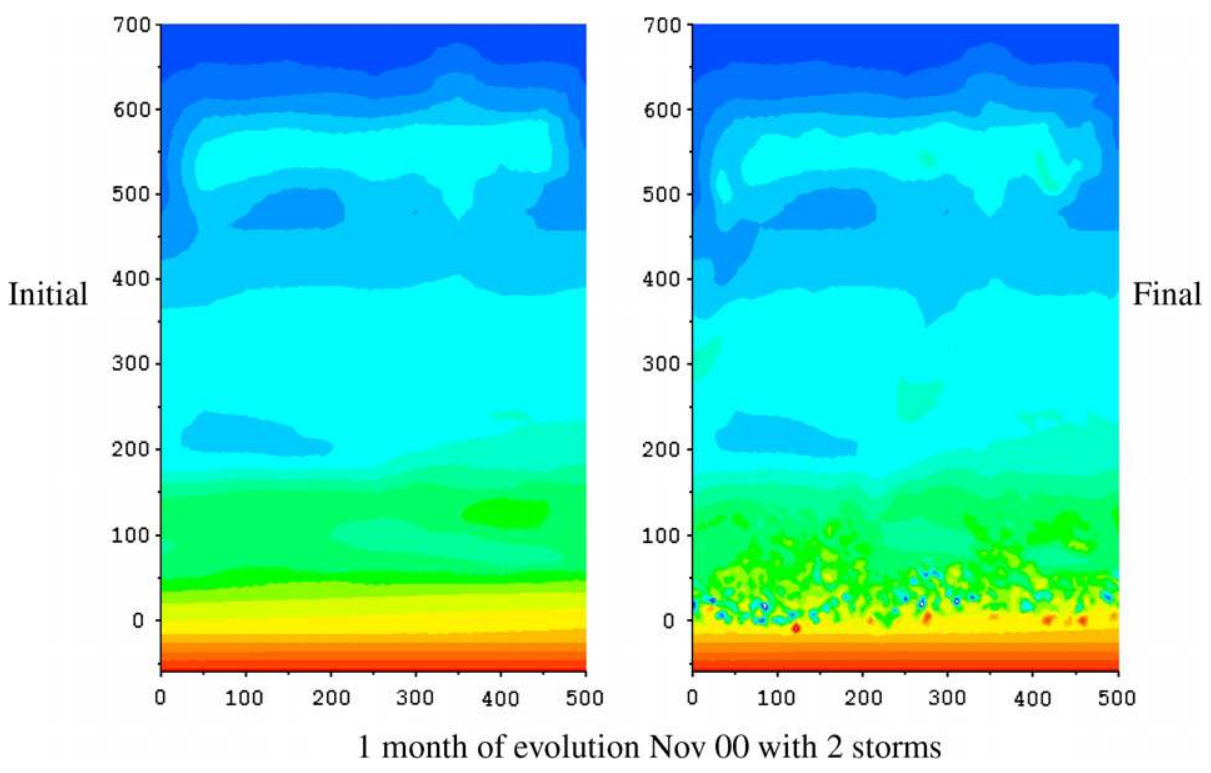

Fig. 6. Iso-bathymetry of a monthly simulation from the 4 November to the 25 November 2000 with nourishment and with a two consecutive storms.
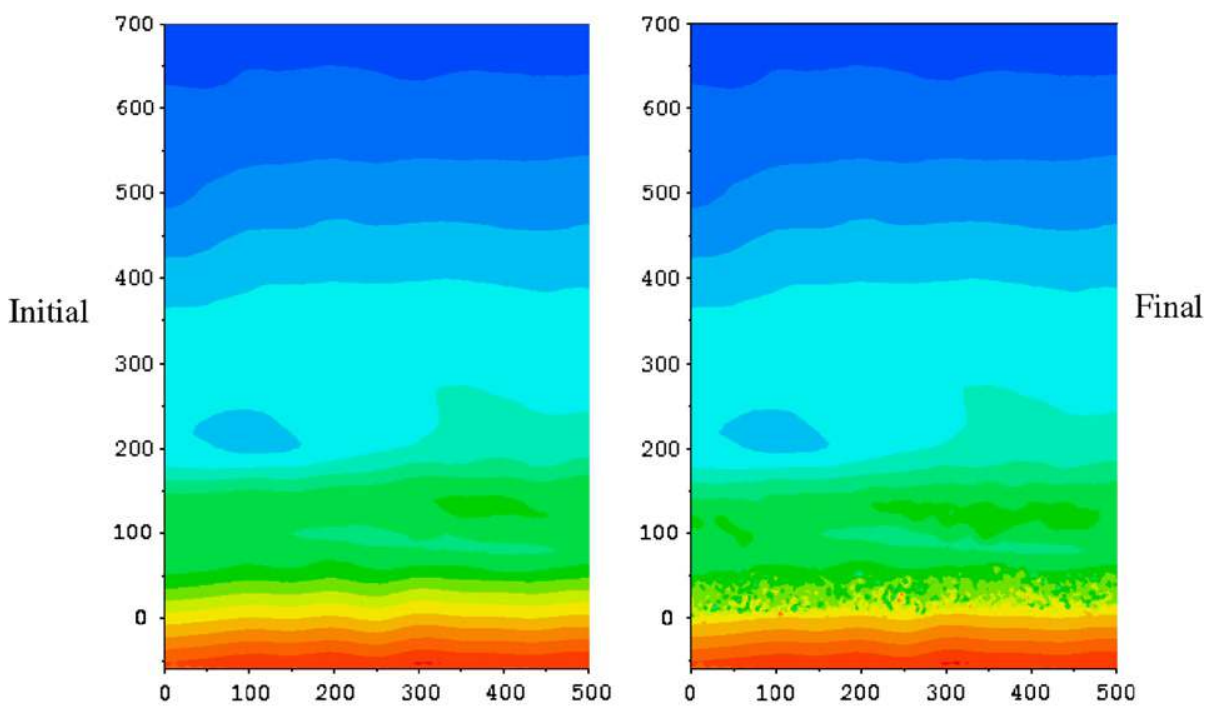

1 month of evolution Nov 00 with 1 event / day

Fig. 7. Iso-bathymetry of a monthly simulation from the 4 November to the 25 November 2000 without nourishment and with one meteorological event per day. 

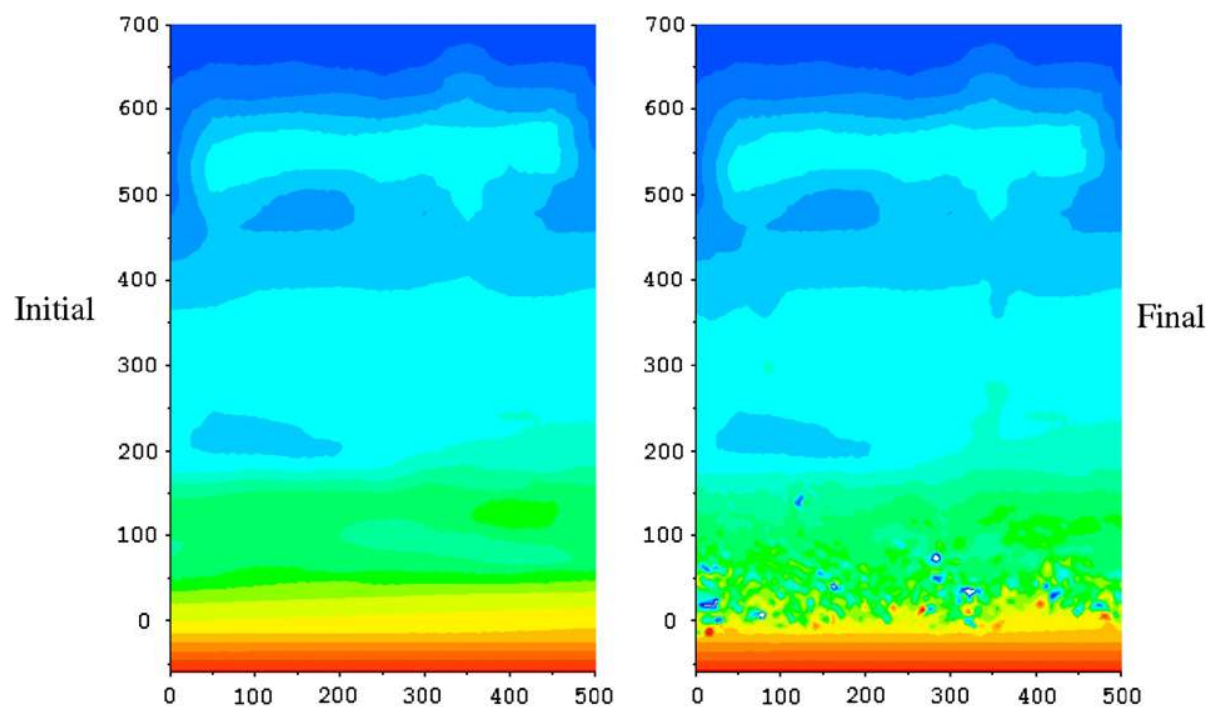

1 Year of evolution Nov 99 to Oct 00 with nourishment

Fig. 8. Iso-bathymetry of a yearly simulation from November 1999 to October 2000 with nourishment.

nourishment and with a cut out of 48 events. The simulation took $24 \mathrm{~h}$ on a $2.36 \mathrm{GHz}$ processor. The aim was to find at the same time the best accuracy of the yearly sea bed evolution and the lowest computational time. The other main goal was to be able to predict the best placement of the nourishment bar to protect the beach over five to ten years.

\section{Conclusion}

The interesting thing about this study is that we could compare our numerical results to the in situ data. Then, it could be easier to modulate time steps to have the most realistic results. A modified 2DH morphodynamical model was employed to simulate the evolution of large-scale features with major implications for beach nourishment. The study was focused on modelling the evolution of the sea bed and artificial material in the near shore region, extracting or adding material to the natural bars, and quantifying how the profile responds to different wave climates and nourishment placements. The simulated results were compared with field data from a Mediterranean beach over storm, monthly and yearly time scales. The results are good in terms of quality and also in terms of quantity for the velocity field due to waves. The next step of the study will be to simulate a large number of seasons from the year 1994 to 2005 to be able to elaborate a criterion for the meteorological cut out. The second goal is to predict the next five years with different nourishment placements to have a good strategy for beach protection.

\section{Acknowledgements}

This paper is largely based on research work carried out in the task group Coastal Morphology of the LITEAU program supported by the French Government and the HUMOR program supported by the European Community.

\section{References}

Bailard, J.A., 1981. An energetic total load sediment transport model for a plane sloping beach. Journal of Geophysical Research 86 (C11), 10938-10954.

Camenen, B., 2002. Modélisation numérique du transport sédimentaire sur une plage sableuse. Ph.D. Thesis. Université Joseph Fourier, Grenoble, 298p.

Camenen, B., Larroudé, Ph., 2003a. Comparison of sediment transport formulae for a coastal environment. Journal of Coastal Engineering 48, 111-132.

Camenen, B., Larroudé, Ph., 2003b. Un modèle morphologique côtier pour la création de barres rythmiques. Revue française de génie civil, Génie côtier 7, 1099-1116.

Certain, R., 2002, Morphodynamique d'une côte sableuse microtidale à barres: le golfe du Lion (Languedoc-Roussillon). Ph.D. Thesis. University of Perpignan, $199 \mathrm{p}$

Certain, R., Barusseau, J.P., 2006. Conceptual Modelling of Straight Sand Bars Morphodynamics for a Microtidal Beach (Gulf of Lions, France). ICCE, San Diego.

Dally, W.R., Dean, R.G., Dalrymple, R.A., 1984. A Model for Breaker Decay on Beaches. In: 19th Coastal Engineering Conference Proceeding. ASCE, pp. 82-88.

De Vriend, H.J., 1987. 2DH Mathematical modelling of morphological evolutions in shallow water. Coastal Engineering 11, 1-27.

De Vriend, H.J., Stive, M.J.F., 1987. Quasi-3D modelling of nearshore currents. Coastal Engineering 11, 565-601.

Dibajnia, M., Watanabe, A., 1992. Sheet flow under nonlinear waves and currents Coastal Engineering, 2015-2029.

Falqués, A. et al., 2008. Rhythmic surf zone bars and morphodynamic selforganization. Coastal Engineering.

Hamm, L., Capobianco, M., Dette, H.H., Lechuga, A., Spanhoff, R., Stive, M.J.F., 2002. A summary of European experience with shore nourishment. Coastal Engineering 47, 237-264.

Hervouet, J.M., 2007. Hydrodynamics of Free Surface Flows: Modelling with the Finite Element Method. John Wiley \& Sons., 360p.

Larroudé, Ph., Camenen, B., 2004. 2DH and multi1DH morphological model for medium term evolution of large scale features and nourishment in the nearshore region: application to TrucVert and Corniche beach (France) and la Barrosa beach (Spain). In: 29th International Conference on Coastal Engineering. ASCE, Lisbon.

LNHE-Chatou, 2002, Telemac2d - modelisation system of Telemac, version 5.2 user-validation manual. Technical report, edf-gdf.

LNHE-Chatou, 2002, Sisyphe - modelisation system of Telemac, version 5.2 - uservalidation manual. Technical report, edf-gdf.

LNHE-Chatou, 2002, Artemis - modelisation system of Telemac, version 5.2 - uservalidation manual, Technical report, edf-gdf.

Longuet Higgins, M.S., 1970. Longshore currents generated by obliquely incident sea waves. Journal of Geophysical Research 75 (33), 60778-60801.

Svendsen, I.A., 1984. Mass flux and undertow in the surf zone. Coastal Engineering 8, 347-365. 